\title{
MAGNETIC TESTING OF STRAIGHT RODS IN INTENSE FIELDS
}

By W. L. Cheney

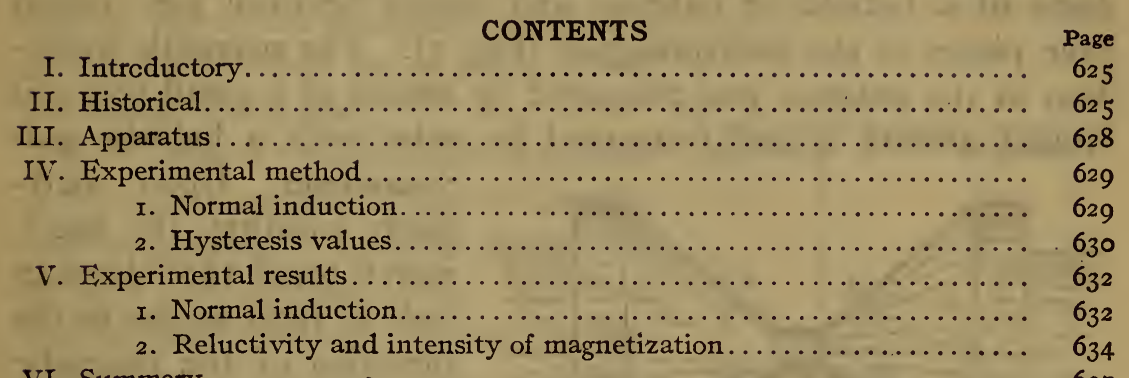

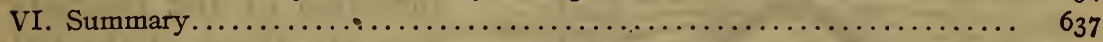

\section{INTRODUCTORY}

The usual types of permeameter, for the measurement of the magnetic properties of iron and steel bars, do not permit the magnetizing force to be carried to very high values. The Burrows permeameter, ${ }^{1}$ for example, is limited to $\mathrm{H}=300$ gausses. Frequently in the testing of the magnetic properties of fairly long straight rods, it is desirable to carry the magnetizing force considerably higher in order to determine the saturation intensity of magnetization. The majority of methods for doing this (vide infra) necessitate the use of very small specimens and, therefore, preclude the possibility of comparing results for low fields with similar results obtained with a standard permeameter. The solenoid method is not entirely satisfactory on account of the demagnetizing factor of the specimen.

In view of these facts, a method suitable for magnetic measurements of long straight bars of iron or steel in intense fields has been developed.

\section{HISTORICAL}

Early experiments to ascertain the intensity of magnetization due to high magnetizing forces were made principally upon specimens either in the form of rings or toroids ${ }^{2}$ or with a long 
rod in a solenoid. ${ }^{3}$ The results obtained by these early experimenters have since been found not to be very accurate.

In I 887 Ewing and Low ${ }^{4}$ developed the well-known "isthmus method" for testing the permeability of ferromagnetic materials under the influence of intense fields. A strong electromagnet was used because in the air space between the pole pieces there can be produced more easily a magnetic field of much greater intensity than in a magnetizing coil where the field is due to the direct action of the electric current. The specimen was in the form of a bobbin or isthmus and placed between the conical pole pieces of the electromagnet (Fig. I). The magnetic induction in the isthmus was measured by means of a small test coil wound around it and connected in series with a ballistic gal-

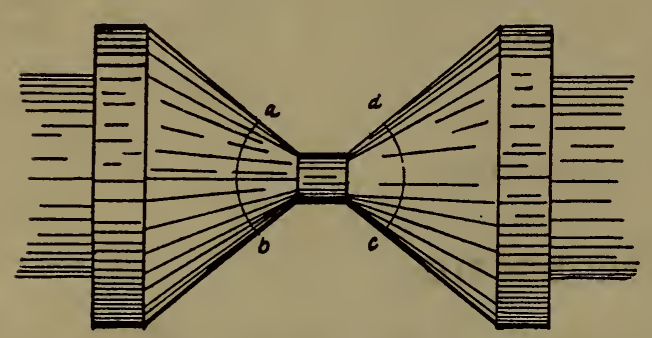

Fig. I.-Illustrating the "isthmus" as used by Ewing and Low vanometer. Upon suddenly rotating the specimen through $180^{\circ}$ about an axis at right angles to the direction of the magnetic flux, the throw of the ballistic galvanometer (previously calibrated), indicated the induction in the specimen. To permit the rotation, the tips of the pole pieces were bored through transversely by a circular hole $a b c d$.

To determine the value of the magnetizing force $(\mathrm{H})$, a second coil surrounding the first was used. The difference in magnitude of the throws of the galvanometer caused by the two coils respectively is proportional to the flux through the air space between the two coils, and can be easily calculated when the difference in the area turns of the coils is known. When there is a uniform magnetic field between the pole pieces, the magnetic flux through. the space included by the two coils is probably only a very little greater than the mean force within the metal itself, hence may be taken as a measure of the latter.

Du Bois ${ }^{5}$ employed an optical method for determining the intensity of magnetization of iron in strong fields, having first examined the material in the weaker fields of a solenoid. Similar experiments were also carried out by Roessler. ${ }^{\circ}$

\footnotetext{
Weber; 2884 .

- Ewing, Magnetic Induction in Iron and Other Metals, Dp. $136-158$.

- Du Bois, Phil. Mag., 29, p. 253 , 1890.

- Roessler, Elektrotech. Zeit., 14, r893.
} 
$\mathrm{Du}$ Bois and Jones ${ }^{7}$ tested specimens between the conical pole pieces of an electromagnet of the Du Bois type. They measured ballistically the change in induction upon suddenly withdrawing the specimen, which formed a part of the isthmus, through a hole in one of the pole pieces.

Weiss ${ }^{8}$ employed small ellipsoids of revolution and placed them symmetrically between the flat pole pieces of an electromagnet of great power. The ellipsoid was suddenly extracted from the field through a hole in the axis of one of the pole pieces while the change in flux was measured by a test coil outside the iron.

B. O. Peirce ${ }^{9}$ studied the magnetic properties, particularly the reluctivity and permeability, of some specimens of very pure Norway iron. He used the isthmus method, having for his apparatus a massive yoke weighing about $300 \mathrm{~kg}$, excited by a current through a coil of 2956 turns wound on spools, as shown in Figure 2. The specimens were of two forms. The first was a cylinder about $1.27 \mathrm{~cm}$ in diameter and about $15 \mathrm{~cm}$ long. Its ends were tapered to fit snugly into sockets in the conical ends of the pole pieces. The

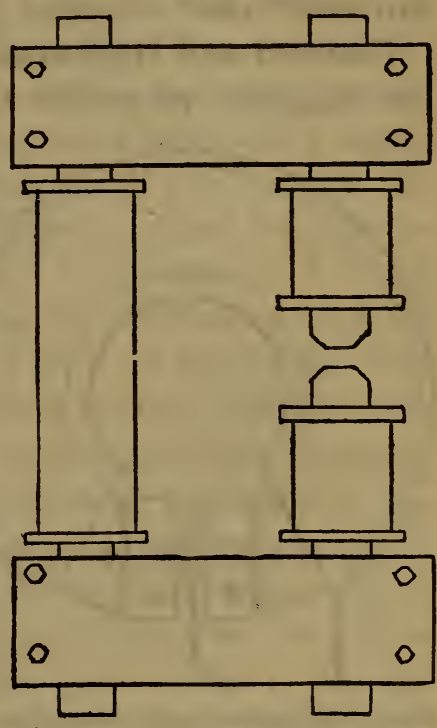

FIG. 2.- Showing the form of the yoke of B.O. Peirce other form was much shorter, the exposed portion being constricted to a smaller diameter than the remainder of the specimen.

Instead of reversing the specimen in the magnetic field, as did Ewing and Low, Peirce reversed the magnetic field by reversing the current through the windings of the electromagnet. $\mathrm{He}$ found that this worked satisfactorily, provided he used a ballistic galvanometer whose period was appreciably greater than the time lag of the electromagnet. He employed the same method as Ewing and Low for determining $B$ and $H$, the latter being measured by connecting two coils in opposition, so that the throw of the galvanometer was proportional to the flux in the annular space between them.

' Du Bois and Jones, Elekt. Zeit., 17, p. 543; 1896 . Electrician, 37, p. 595; 1896.

8 P. Weiss, Comptes Rendus, 145, p. II 55; 1907.

B. O. Peirce, Am. Acad. Arts and Sci., Proc., 44, p. 354; 1909. Am. Jour. of Sci., 27, p. 273, x909; 28, p. I, 1909. 
In some of his subsequent experiments Peirce ${ }^{10}$ used a large magnetizing solenoid to supplement his observations with the modified isthmus method.

Gumlich ${ }^{11}$ employed the isthmus method for determining the intensity of magnetization of some very carefully prepared specimens of iron. He used an electromagnet of the Du Bois type and suddenly reversed the isthmus (specimens $28 \mathrm{~mm}$ long and $3 \mathrm{~mm}$ diameter), according to the method of Ewing and Low. Later, Gumlich ${ }^{12}$ used a special yoke which proved satisfactory.

Hadfield and Hopkinson, ${ }^{13}$ in a very extensive investigation of the magnetic properties of iron alloys, used a modified isthmus

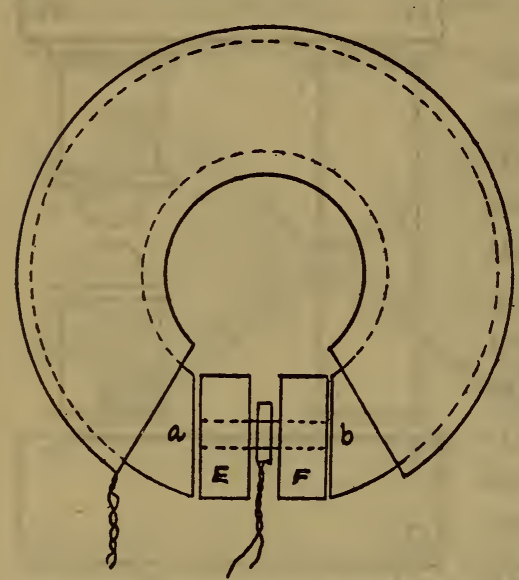

Fig. 3.-Illustrating the form of the electromagnet used by Campbell and Dye method somewhat after the manner of Peirce, but used very much smaller specimens.

Further developments were made by Campbell and Dye, ${ }^{14}$ the form of whose electromagnet is shown in Fig. 3. The specimens tested were either in the form of a rod $7 \mathrm{~cm}$ long and $0.5 \mathrm{~cm}$ in diameter, or an equivalent bundle of strips or wires. The specimen was fitted into thick, soft iron disks $E$ and $F$, which formed the pole pieces. These disks did not touch the magnet poles but were separated from them by a small air gap. In the middle portion of the test specimen was a coil of 40 turns of wire used for measuring $B$, and three outer successively larger coaxial coils of 400 turns each used differentially to determine $H$. By using alternately one set of coils and then the other, the uniformity of the field between the poles of the electromagnet could be tested.

\section{APPARATUS}

The apparatus used in the present investigation consists essentially of an electromagnet of the Du Bois type (Fig. 4) with flat pole pieces, separated by an air gap of approximately $2 \mathrm{~cm}$ and pierced coaxially so that a rod $6 \mathrm{~mm}$ in diameter and several

${ }^{10}$ B. O. Peirce, Am. Acad. Arts and Sci., Proc., 49, p. Ir7; 1913.

II E. Gumlich, Elekt. Zeit., 30, pp. 1065-1067; 1909.

12 E. Gumlich, Archiv. für Elektr., 2, p. 46I; 1913-1914.

18 Hadfield and Hopkinson, Inst. of Elec. Eng. Jour., 46, p. 235; 1911.

${ }^{14}$ Campbell and Dye Inst. of Elec. Eng. Jour., 54, p. 35; 19r5. 
Scientific Papers of the Bureau of Standards, Vol. 15

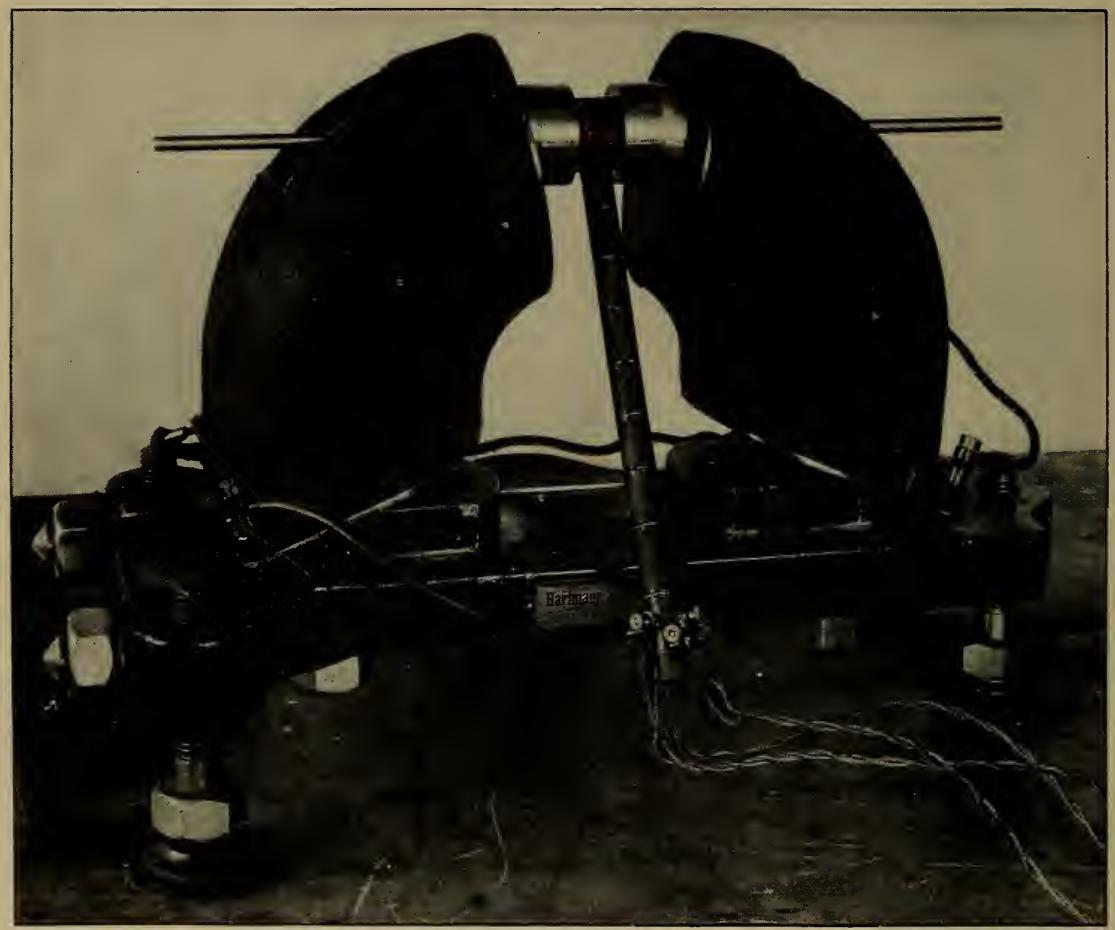

FIG. 4.-Photograph of the Du Bois electromagnet, showing specimen and test coils in place 
centimeters long can be extended through them and the electromagnet. Surrounding the specimen are three coaxial coils wound on brass forms each $\mathrm{I} \mathrm{cm}$ long and having external diameters of $7 \mathrm{~mm}$, $10.5 \mathrm{~mm}$, and $13.2 \mathrm{~mm}$, respectively. Each coil has 100 turns of No. 40 (B. \& S. gage) enameled copper wire. To insure insulation from the brass form, the latter was first wrapped with a thin sheet of paper, and to secure a moisture-free coating of insulating material, the whole coil after winding was well shellacked and baked in an oven at $100^{\circ} \mathrm{C}$ for several hours. To measure the number of area turns of the coils, they were placed in the center of a solenoid and the throw of a ballistic galvanometer upon reversing a known magnetizing force inside the solenoid was compared with the throw observed when the current was reversed through the primary coil of a known mutual inductance.

Fig. 5 is a diagram of the circuits and connections. A Leeds and Northrup, type $R$, ballistic galvanometer, calibrated with the aid of a mutual inductance, is used. There are employed three sensitivities of the galvanometer, regulated by the parallel resistance $R_{\mathrm{p}}$ and the series resistances $R_{\mathrm{h}_{1}}^{\prime}$ and $R_{\mathrm{h}_{2}}^{\prime}$ for low values of $H$, as measured by inner and outer annuluses, respectively, $R_{\mathrm{h}_{1}}$ and $R_{\mathrm{h} 2}$ for high values of $H$, and $R_{\mathrm{b}}$ for $B$, making necessary five secondary circuits in series with the galvanometer. $R_{\mathrm{b}}$ is adjusted so that a reversal of 10 ooo lines of induction per square centimeter gives a throw of $10 \mathrm{~cm}$ of the galvanometer; $R_{\mathrm{h}_{1}}$ and $R_{\mathrm{h}_{2}}$ so that a reversal of a magnetizing force of 1000 gausses gives a deflection of $10 \mathrm{~cm}$; and $R_{\mathrm{h}}{ }_{1}$ and $R_{\mathrm{h}}{ }_{2}$ so that a reversal of 200 gausses gives a throw of $10 \mathrm{~cm}$. In the latter case it is also necessary to increase the magnitude of $R_{\mathrm{p}}$.

\section{EXPERIMENTAL METHOD}

\section{NORMAL INDUCTION}

To determine the value of the magnetic induction $B$, the inner coil is connected in series with the ballistic galvanometer. Upon suddenly reversing the current in the windings of the electromagnet the throw of the ballistic galvanometer is proportional to the induction in the specimen. To measure the magnetizing force $H$, the inner and middle coils are connected differentially, so that the throw of the galvanometer is proportional to the flux in the annular space between the coils. To check the uniformity of the field, the middle and outer coils are connected in a similar manner and the throw again observed. Observations obtained by the 
two sets of coils seldom differ by more than 2 per cent and in most cases check much more closely.

By measuring $B$ for successively increasing values of $H$, normal induction curves can be obtained.

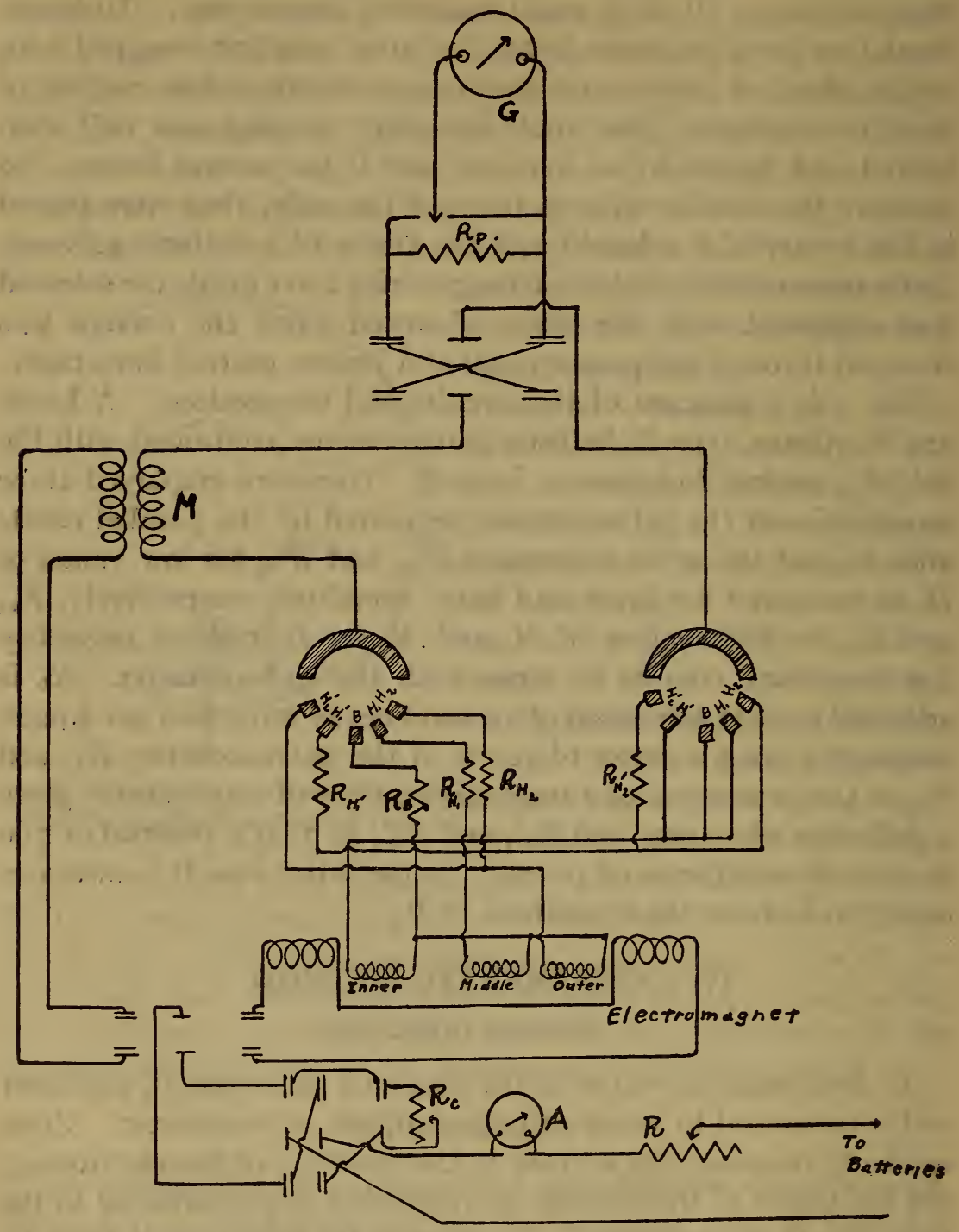

Fig. 5.-Diagram of electrical circuits and connections

\section{HYSTERESIS VALUES}

The part of the whole experiment which requires the greatest care and yields the least accurate results has to do with the measurement of the hysteresis constants, residual induction $\left(B_{\mathbf{r}}\right)$ and the coercive force $\left(H_{\mathrm{c}}\right)$. 
Consider the hysteresis loop (Fig. 6) and suppose the induction is at the tip $B_{\mathrm{m}}$ for a given maximum magnetizing force $H_{\mathrm{m}}$. By reversing the current in the windings of the electromagnet, $B$ changes from $B_{\mathrm{m}}$ to $-B_{\mathrm{m}}$ and $H$ changes from $H_{\mathrm{m}}$ to $-H_{\mathrm{m}}$. Now, if instead of reversing the current, the circuit is suddenly broken, $H$ is reduced to zero and $B$ changes from $B_{\mathrm{m}}$ to $B_{\mathbf{r}}$ which can be located on the curve. In practice, however, the

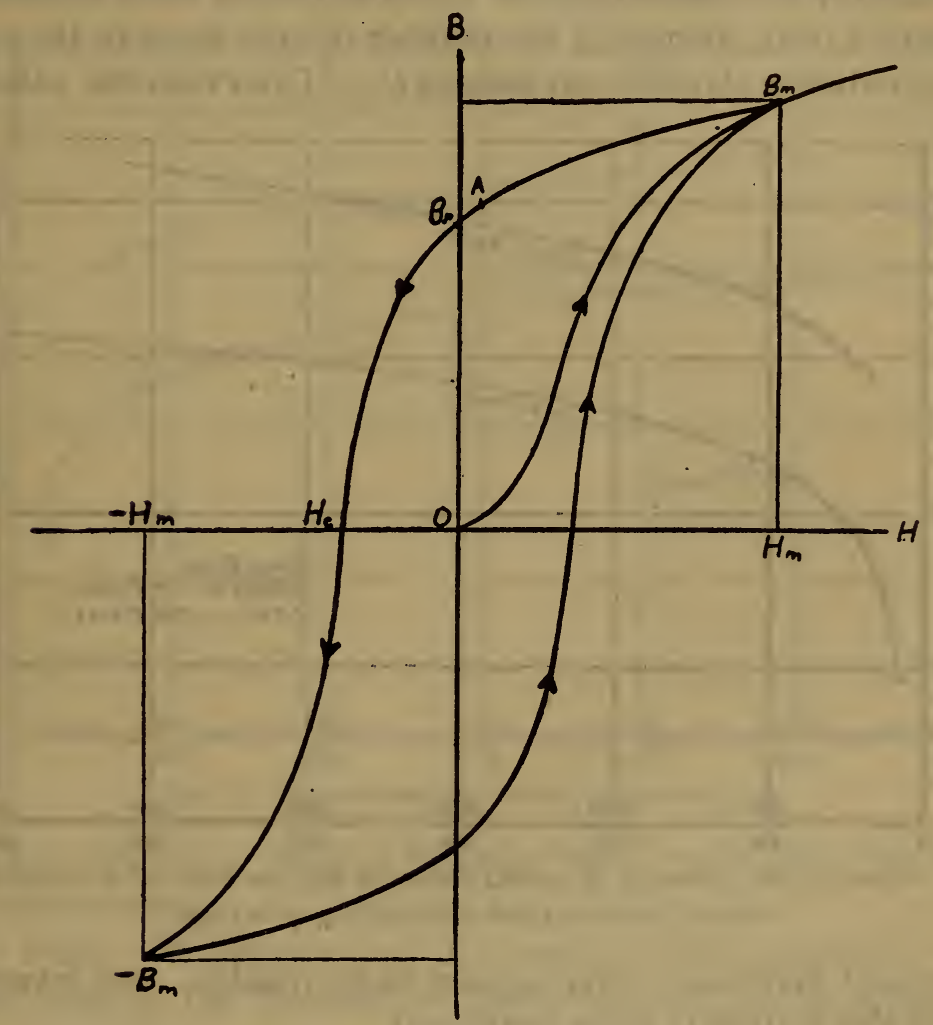

Fig. 6.-Characteristic hysteresis loop

point $B_{\mathbf{r}}$ is not quite reached on account of the small residual field in the electromagnet - but, rather, some point $A$. This point, however, does not differ very greatly from the true value of the residual induction, particularly in the case of hard materials, since the curve is quite flat in this region.

To determine the coercive force, the galvanometer is connected in series with the $B$ coil. Resistance $\left(R_{\mathrm{c}}\right)$ is added to the primary circuit simultaneously upon reversal of the current, so that instead of passing from $B_{\mathrm{m}}$ to $-B_{\mathrm{m}}$ the induction changes from $B_{\mathrm{m}}$ to 
zero, and the magnetizing force from a large value $H_{\mathrm{m}}$ to a small negative value $H_{\mathrm{c}}$. Now, on suddenly breaking the circuit, $H$ changes from $H_{\mathrm{o}}$ to zero, from which the coercive force may be found, although it is difficult to determine very accurately owing. to the small order of magnitude of the throw of the galvanometer, which is hardly sensitive enough for such small values as occur in the case of soft material. The galvanometer throw is increased considerably by connecting the inner and outer coils together in opposition (thus increasing the number of area turns in the annulus) by reducing $R_{\mathrm{h}}$ and by increasing $R_{\mathrm{p}}$. Even then the values of

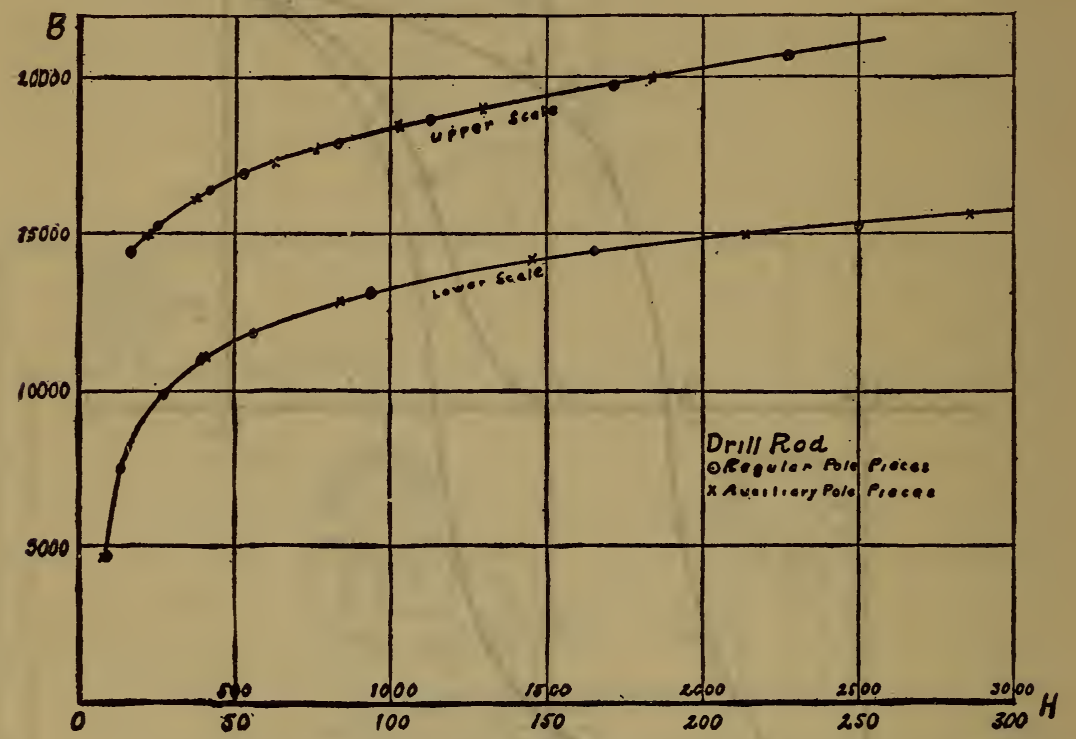

FIG. 7.-Showing the agreement of normal induction data for drill rod as obtained with regular pole pieces and with auxiliary pole pieces

$H_{\mathrm{o}}$ for soft materials do not appear to be reliable. An investigation of this feature is being continued.

\section{EXPERIMENTAL RESULTS}

\section{NORMAL INDUCTION}

It will be recalled that Campbell and Dye ${ }^{15}$ used a short rod, placed in auxiliary pole pieces of the electromagnet. To compare the results obtained by their method with those obtained by the present method, two auxiliary pole pieces were prepared and introduced as in Fig. 3. After testing a specimen of drill 
rod, $6 \mathrm{~cm}$ long, the auxiliary pole pieces were removed and the air gap of the electromagnet adjusted so that $2 \mathrm{~cm}$ of each end of the specimen projected into the regular pole pieces. The normal induction curve was again observed. No difference could be found in the case of the two sets of observations as illustrated in Fig. 7 .

A series of tests were made upon 12 rods $6 \mathrm{~mm}$ in diameter and $35 \mathrm{~cm}$ long. Four of these, Nos. 293-296, were of Norway

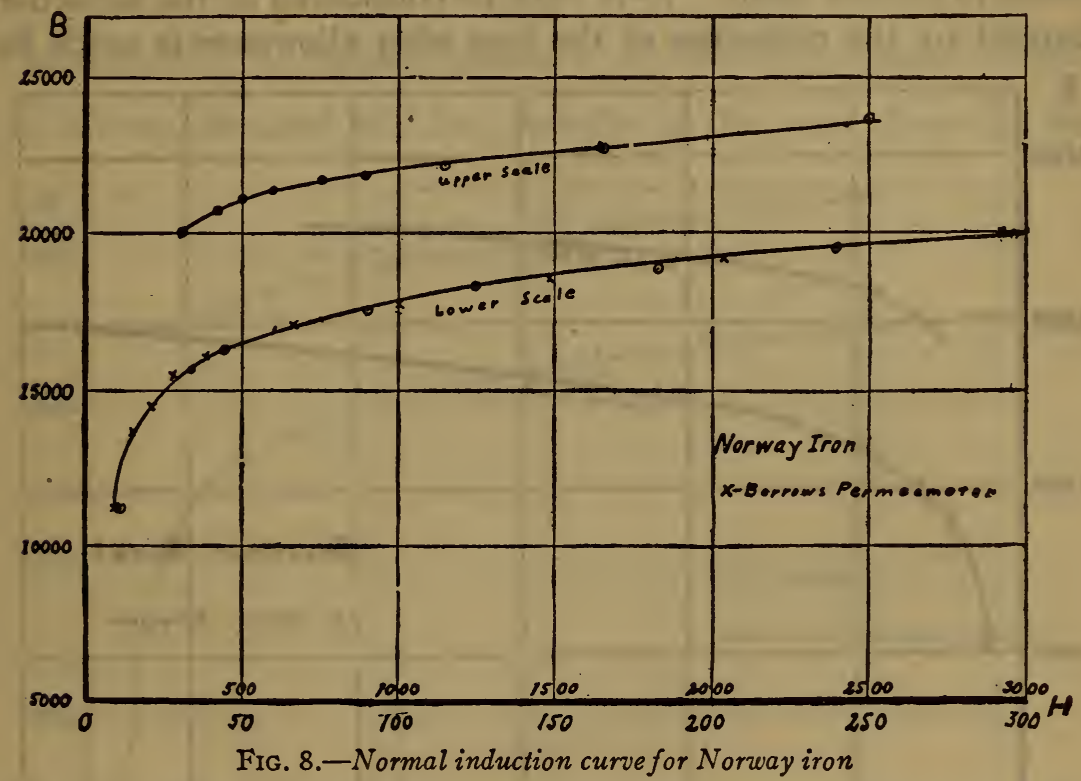

iron, four (297-300) were of Bessemer steel, while four (30r-304) were of tool steel.

To check the accuracy of the results, these specimens were tested both in the Burrows permeameter and in the apparatus herein described. Figs. 8, 9, and ro show typical $B-H$ curves obtained in this manner. An inspection of these curves reveals the unusually good agreement between the results obtained by the two types of apparatus. It is assumed, therefore, that the higher values of the induction, which can not be measured in the Burrows apparatus, are correct.

Fig. I I shows the curves for normal induction and permeability for a specimen of unusually hard magnet steel known as " K S" magnet steel and prepared by Prof. Honda. 


\section{RELUCTIVITY AND INTENSITY OF MAGNETIZATION}

The reluctivity $(\rho)$ is defined by the relationship

$$
\rho=\frac{H}{B}=\frac{1}{\mu}
$$

The magnetic induction $(B)$ increases indefinitely as the magnetizing force $(H)$ is increased, but it is found that if $H$ be subtracted from the value of $B, B-H$ reaches a finite saturation value in intense fields. $B-H$ may be considered as the induction carried by the molecules of the iron after allowance is made for

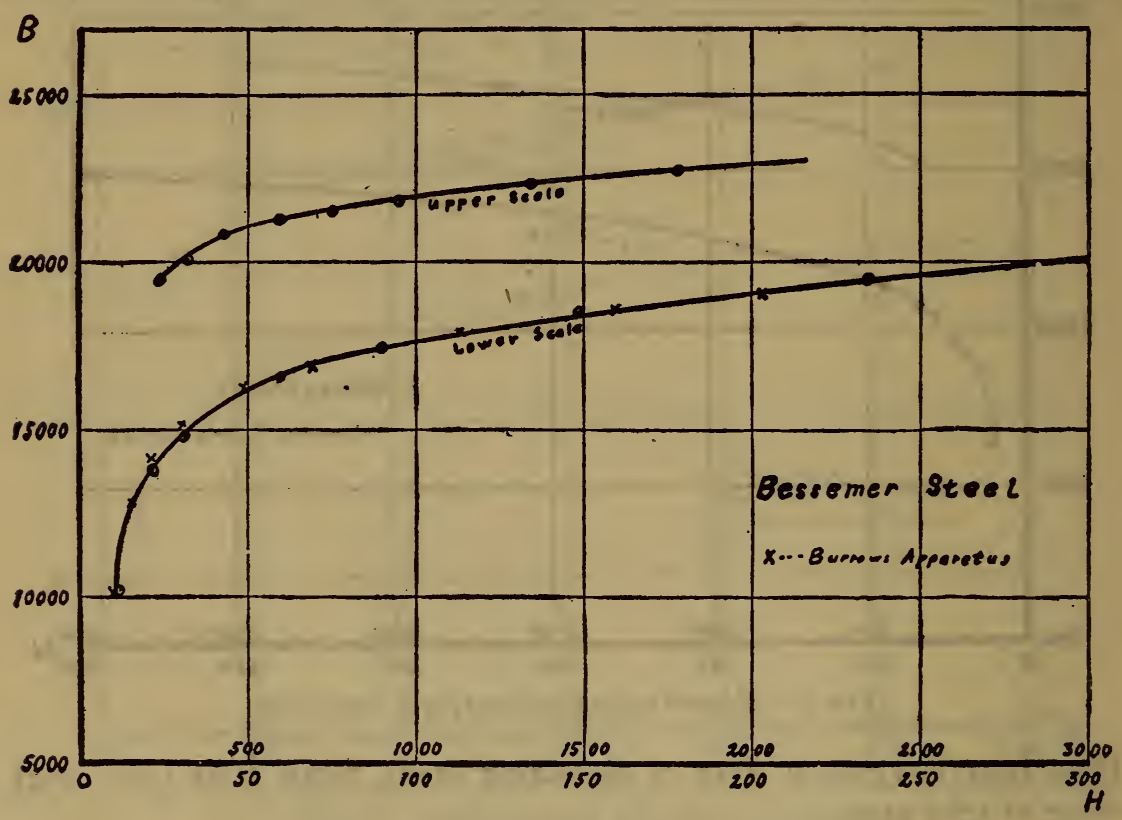

FIG. 9.-Normal induction curve for Bessemer steel

the flux in the space occupied by the material but independent of it. Replacing $B$ by $B-H$,

$$
\rho_{0}=\frac{H}{B-H}
$$

and is called the "metallic reluctivity." Kennelly ${ }^{10}$ has shown that $\rho_{0}$ plotted against $H$ as the independent variable gives a straight line (except near the origin) whose equation may be written as

From the usual equation

$$
\rho_{0}=a+b H
$$

$$
B=H+4 \pi I
$$


the intensity of magnetization may be written

$$
I=\frac{B-H}{4 \pi}
$$

and can be easily calculated for successively higher values of $H$. The reciprocal of the susceptibility $(k)$ is given by

$$
\frac{\mathrm{I}}{k}=\frac{H}{I}=\frac{4 \pi H}{B-H}=4 \pi \rho_{\mathrm{o}}
$$

Therefore, if $\frac{\mathrm{I}}{k}$ be plotted against $H$ as the independent variable, the curves obtained will be precisely of the same shape as the

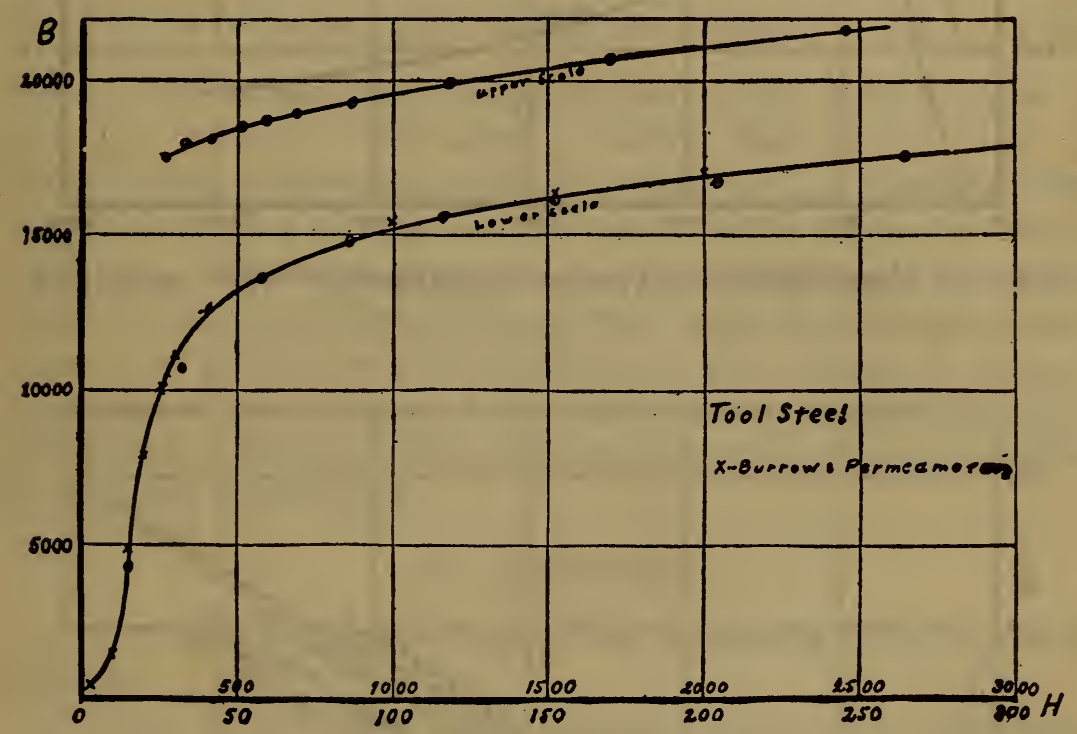

Fig. I0.-Normal induction curve for tool steel

$\rho_{0}-H$ curves and such graphs are shown for five different materials in Fig. 12 , the ordinates representing the reciprocal of the susceptibility, and the abscissæ the field strength.

Now, by calculating the reciprocal of the slope of these graphs, the value for the maximum value of the intensity of magnetization is determined. This has been done for a number of specimens and the results are incorporated in Table $I$ together with observed values for $H=2000$. 


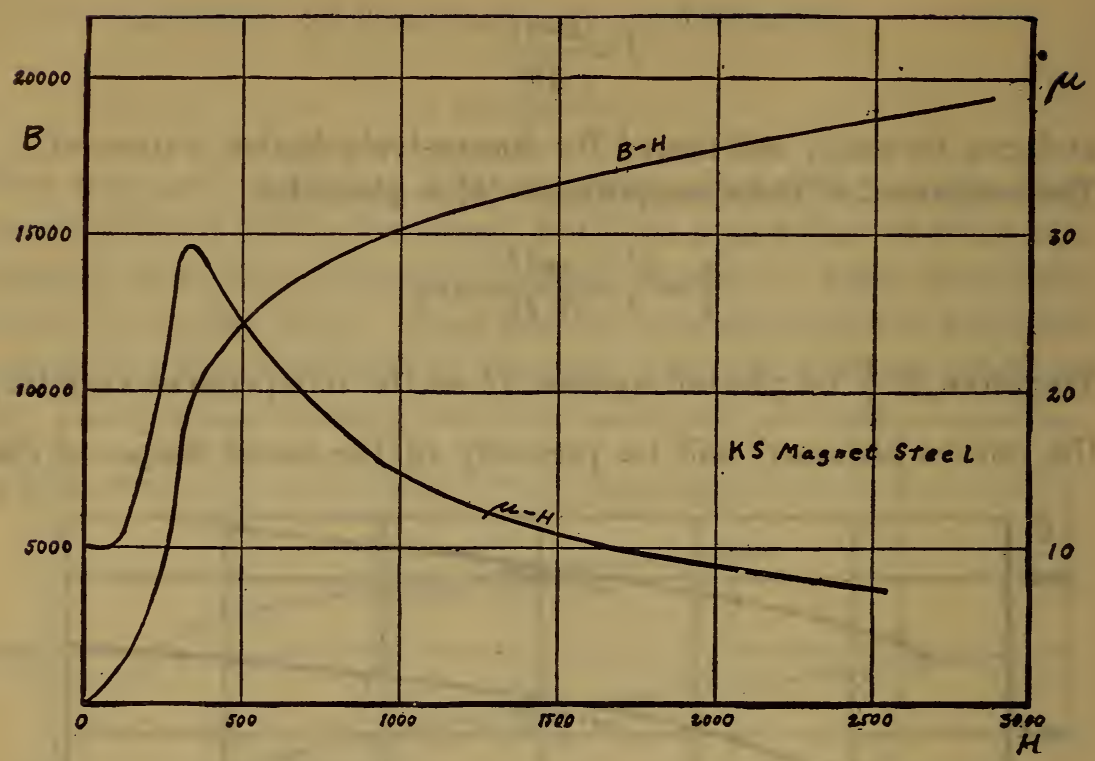

FIG. II.-Normal induction and permeability for curves for " $K S$ " magnet steel

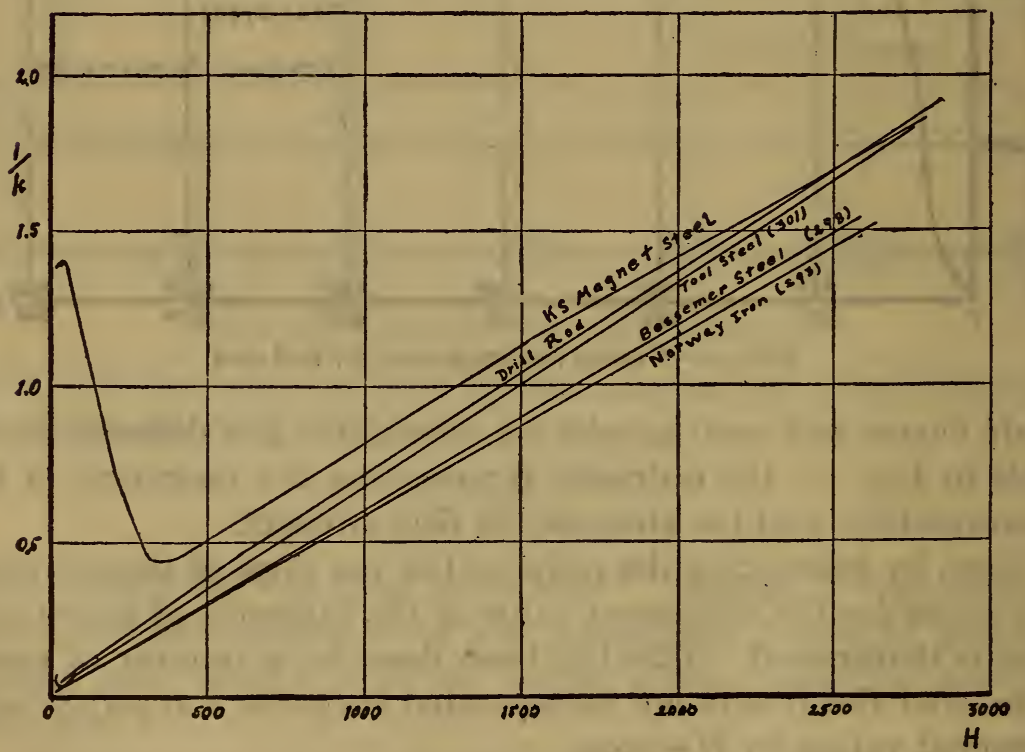

FIG. 12.-Showing the reciprocal of the susceptibility plotted against the magnetizing force 
TABLE 1

\begin{tabular}{|c|c|c|c|c|c|c|c|}
\hline $\begin{array}{l}\text { Speci- } \\
\text { men } \\
\text { No. }\end{array}$ & Material & $\begin{array}{l}\text { Imax } \\
\text { (calcu- } \\
\text { lated) }\end{array}$ & $\begin{array}{c}\mathbf{I} \text { for } \\
\mathbf{H}=2000\end{array}$ & $\begin{array}{l}\text { Specl- } \\
\text { men } \\
\text { No. }\end{array}$ & Materlal & $\begin{array}{l}\text { Imax } \\
\text { (calcu- } \\
\text { lated) }\end{array}$ & $\begin{array}{c}I \text { for } \\
\mathbf{H}=2000\end{array}$ \\
\hline $293 \ldots$ & Norway iron........ & 1747 & 1725 & $301 \ldots$ & Tool steel..... & 1579 & 1490 \\
\hline $294 . .$. & .....do................. & 1701 & 1686 & $302 \ldots$ & .....do................ & 1564 & 1525 \\
\hline $295 \ldots \ldots$ & .....do............... & 1679 & 1672 & $303 \ldots .$. & .....do.............. & 1545 & 1515 \\
\hline $296 \ldots \ldots$ & .....do................ & 1729 & 1723 & $304 \ldots .$. & .....do.............. & 1564 & 1530 \\
\hline $297 \ldots . .$. & Bessemer steel..... & 1695 & 1665 & & & 1613 & \\
\hline $298 \ldots . .$. & .....do................ & 1672 & 1672 & & K s magnet steel.. & 1795 & 1412 \\
\hline $299 \ldots \ldots$ & .....do............... & 1667 & 1652 & & & 1384 & \\
\hline $300 \ldots .$. & .....do........ & 1698 & 1665 & & Drill rod.. & 1534 & 1465 \\
\hline
\end{tabular}

In the case of the $\mathrm{K} \mathrm{S}$ magnet steel and drill rod, the slope of

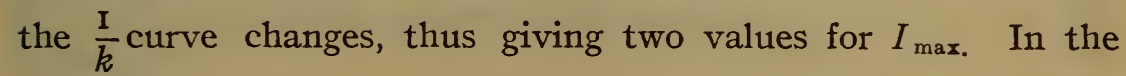
case of the former this change occurs in the neighborhood of $H=\mathrm{I} 500$, while for the latter it occurs near $H=600$. B. O. Peirce ${ }^{17}$ has pointed out that the value of $I_{\max }$ obtained from the lower portion of the curve is less than the saturation value, while $I_{\max }$ calculated from the upper portion of the curve where the slope is different is somewhat larger than the saturation value. As pointed out by Steinmetz ${ }^{18}$ this change in slope is indicative of the presence of two constituents of differing degrees of hardness, which reach the maximum intensity of magnetization for different values of $H$.

\section{SUMMARY}

I. A resume of previous methods of measuring high inductions is given.

2. A new modification of the isthmus method which is adapted to the testing of long straight specimens is described.

3. Data are given to illustrate the accuracy of the method as compared with standard methods.

4. Normal induction, intensity of magnetization, and reluctivity data are discussed for various materials.

The writer is indebted to R. L. Sanford and Dr. C. Nusbaum for valuable suggestions throughout the course of the experiments.

WASHington, August 29, I919.

${ }^{17}$ B. O. Peirce, Am. Acad. Arts and Sci., Proc., 49, pp. 117-146; 1913.

18 Steinmetz, Gen. Elec. Rev., 20, p. 135; 1917 . 